\title{
La influencia de Tiwanaku en San Pedro de Atacama: Una investigación utilizando el análisis de isótopos del estroncio
}

KeLLy J. KNUDSON ${ }^{1}$

\section{RESUMEN}

El alcance de la influencia de Tiwanaku en San Pedro de Atacama durante el Horizonte Medio (500-1000 AC) ha sido altamente debatido. Mientras algunos expertos han enfatizado la existencia de una relación indirecta basada en interacciones religiosas y/o económicas, otros argumentan que un grupo de colonos de Tiwanaku estuvo físicamente presente en San Pedro de Atacama. En este estudio veremos cómo la técnica del análisis de isótopos del estroncio ha sido utilizada para identificar el origen geográfico de algunos individuos enterrados en Coyo-3, Coyo Oriental y Solcor-3. El estudio no identificó individuos que hubieran vivido en la cuenca del lago Titicaca durante los primeros años de sus vidas, debilitando la hipótesis que sostiene que en San Pedro de Atacama se estableció una colonia del Estado altiplánico.

Palabras claves: Tiwanaku-San Pedro de Atacama-análisis de isótopos del estroncio - química ósea.

\begin{abstract}
The nature of Tiwanaku influence in the San Pedro de Atacama region during the Middle Horizon (AD 5001000) has been widely debated. While some scholars have emphasized an indirect relationship based on religious and/or economic interactions, others have argues that a population of Tiwanaku colonists was physically present in San Pedro de Atacama. Here, strontium isotope analysis is used to identity the geographic origin of individuals buried in Coyo-3, Coyo Oriental and Solcor-3. This study identified no individuals who may have lived in the southeastern Lake Titicaca Basin during the first few years of their life, weakening the hypothesis that San Pedro de Atacama was a Tiwanaku colony.
\end{abstract}

Key words: Tiwanaku - San Pedro de Atacama - strontium isotope analysis - bone chemistry.

Recibido: septiembre de 2005. Aceptado: enero 2006.

1 Center for Bioarchaeological Research, School of Human Evolution and Social Change, Arizona State University. PO

\section{Introducción}

En los oasis de San Pedro de Atacama en el norte de Chile, varios especialistas han identificado la existencia de material cultural tiwanakota en los cementerios (Le Paige 1961; Rivera 1975; Berenguer 1978; Berenguer et al. 1980; Serracino 1980; Orellana 1984, 1985; Thomas et al. 1985; Oakland 1986b, 1986a; Berenguer y Dauelsberg 1988; Núñez 1991; Torres y Conklin 1995; Llagostera 1996; Browman 1997; Uribe y Agüero 2001; Goldstein y Rivera 2005). Sin embargo, la relación entre San Pedro de Atacama y el Estado Tiwanaku, centralizado en el sitio homónimo, en la cuenca del lago Titicaca, en la actual Bolivia, es aún muy polémica (Figura 1). Por ejemplo, algunos investigadores han planteado que en San Pedro de Atacama se establecieron colonias tiwanakotas (Oakland 1992; Kolata 1993a, 1993b), mientras que otros argumentan que es únicamente el contacto indirecto lo que caracteriza la relación entre individuos de las dos regiones (Berenguer et al. 1980; Berenguer y Dauelsberg 1988; Torres y Conklin 1995; Llagostera 1996; Browman 1997). Los arqueólogos pueden comprobar sus hipótesis acerca de la relación entre San Pedro de Atacama y Tiwanaku mediante el análisis químico del esmalte dental y de huesos humanos provenientes de sitios arqueológicos. Más específicamente, el análisis de los isótopos del estroncio puede ayudar a identificar a los individuos enterrados en los cementerios de San Pedro de Atacama, que hubieran vivido en una diferente región geológica de los Andes en los primeros años de sus vidas. A continuación se presentará un breve repaso de la evidencia de la influencia de Tiwanaku en San Pedro de Atacama, seguido de la explicación de la técnica del análisis de los isótopos de estroncio. Luego, se concluirá con la presentación del análisis de isótopos del estroncio de individuos enterrados en los cementerios Coyo-3, Coyo Oriental y Solcor-3, emplazados en los oasis de San Pedro de Atacama.

Box 872402. Tempe, AZ 85287-2402, ESTADOS UNIDOS.

Email: kelly.knudson@asu.edu 


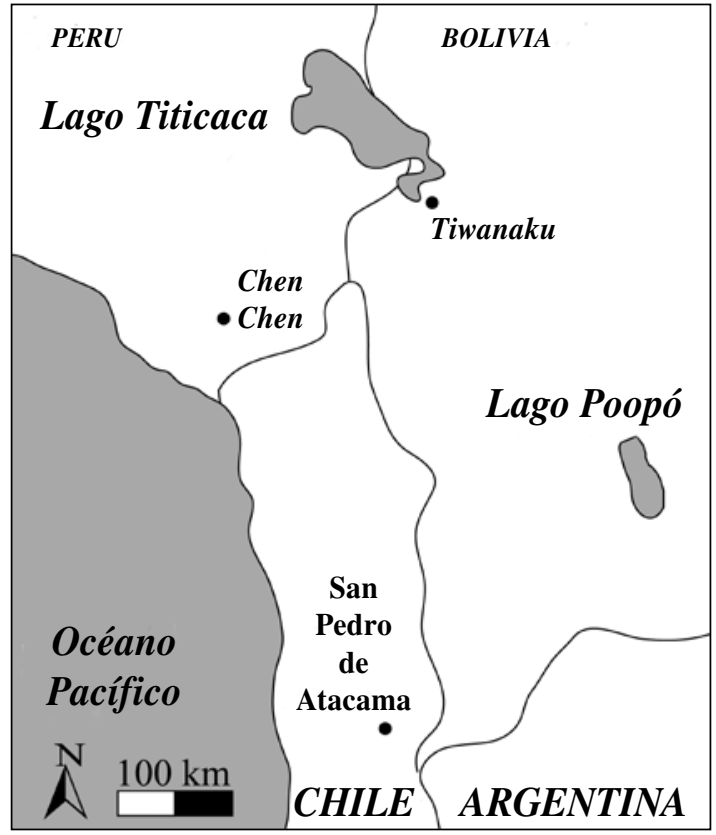

Figura 1. Mapa de los Andes Centro Sur que muestra la ubicación de Tiwanaku y San Pedro de Atacama.

\section{Influencia de Tiwanaku en San Pedro de Atacama: Un breve repaso}

Al contrario que en el drenaje del río Osmore en el sur del Perú, y en el valle de Azapa en el norte de Chile, la evidencia de la influencia de Tiwanaku en San Pedro de Atacama está caracterizada únicamente por la existencia de pequeños artefactos portátiles de estilo Tiwanaku y por la falta de sitios residenciales o ceremoniales del mismo estilo (Le Paige 1961; Rivera 1975; Berenguer 1978; Berenguer et al. 1980; Serracino 1980; Conklin 1983; Orellana 1984, 1985; Thomas et al. 1985; Browman 1986, 1997; Oakland 1986a, 1986b; Berenguer y Dauelsberg 1988; Núñez 1991; Torres y Conklin 1995; Llagostera 1996; Goldstein y Rivera 2005; Young-Sánchez 2005). Por ejemplo, los cementerios Coyo Oriental, Coyo-3 y Solcor-3 contienen individuos enterrados con artefactos de origen local, junto a individuos enterrados con tejidos tiwanakotas y objetos rituales, como tabletas para alucinógenos (Torres 1985, 1987, 2001, 2005; Bravo y Llagostera 1986; Llagostera et al. 1988; Oakland 1992, 1994; Costa y Llagostera 1994; Uribe y Agüero 2001). Otros objetos de estilo tiwanakota, como los tubos óseos pirograbados, keros de oro y cerámica han sido encontrados también, pero en menores cantidades (Le Paige 1961; Stovel 2002; Young-Sánchez 2005).
A pesar de que existe consenso respecto de que artefactos del estilo tiwanakota han sido encontrados junto a artefactos de estilo local en San Pedro de Atacama, la explicación de la presencia de los primeros es muy variada (Torres y Conklin 1995). Algunos investigadores sostienen la hipótesis que estos artefactos llegaron allí debido a las redes de comerciantes, y que fueron intercambiados por metales valiosos y por piedras semipreciosas que existen cerca del oasis (Berenguer et al. 1980; Berenguer y Dauelsberg 1988; Browman 1997). Llagostera (1996), por ejemplo, hace énfasis en las relaciones de poder y en el estatus de los objetos importados, y argumenta que las élites locales adquirían poder al controlar los productos extranjeros. Por el contrario, Stanish (2003) opina que el oasis de San Pedro de Atacama habría sido un área de descanso invaluable para las caravanas de camélidos, y que los comerciantes de Tiwanaku pudieron haber cambiado sus bienes por el acceso a comida, agua y descanso.

Otros investigadores acentúan el contacto indirecto entre Tiwanaku y San Pedro de Atacama (Serracino 1980, 1984; Orellana 1984, 1985; Stovel 2002), argumentando que el Estado Tiwanaku quizás haya constituido una confederación unificada de pequeñas naciones, tales como San Pedro de Atacama, las cuales habrían mantenido su unidad tanto a través de la economía como de la ideología (Orellana 1984, 1985). Stovel (2002) también propone que la relación entre San Pedro y Tiwanaku era de carácter comercial, pero hace énfasis en la existencia de una gran red a lo largo de los Andes Centro Sur.

Finalmente, también San Pedro de Atacama ha sido identificado como socio comercial de Tiwanaku, y como un puesto avanzado en las provincias, donde podían hospedarse pequeños grupos de colonos tiwanakotas (Oakland 1992; Kolata 1993a, 1993b). Sin embargo, la presencia física de inmigrantes del altiplano es bastante discutida. Como evidencia de que grupos de comerciantes o de inmigrantes tiwanakotas estuvieron físicamente presentes en el oasis, algunos expertos apuntan a la presencia de artefactos de estilo Tiwanaku (Berenguer et al. 1980; Benavente et al. 1986; Berenguer y Dauelsberg 1988), de tejidos mortuorios de ese mismo estilo (Oakland 1986a, 1986b, 1992), y también al análisis de distancia biológica de rasgos no métricos del cráneo y estudios de deformación artificial del cráneo (Varela 1997; Varela y Cocilovo 2000). Por otra parte, estudios de distancia biológica de los rasgos craneales no métricos (Llagostera et al. 
1988) y de deformaciones artificiales del cráneo en Solcor-3 (Torres-Rouff 2002) respaldan la hipótesis que algunos de los pobladores nativos de San Pedro, sin vínculo físico con el altiplano, adaptaron artefactos de estilo Tiwanaku. De cualquier forma, aunque hayan habitado individuos provenientes del altiplano en San Pedro de Atacama, no hay señal del aumento de conflictos en el oasis, y de hecho se nota un mejoramiento en la salud general de la población (Costa et al. 1998, 2004; Neves y Costa 1998; Neves et al. 1999).

\section{Coyo-3}

En el cementerio de Coyo-3 las excavaciones dirigidas por Costa y Llagostera revelaron 51 tumbas que contenían 80 individuos en $96 \mathrm{~m}^{2}$ (Costa y Llagostera 1994). De estas tumbas en cistas de forma cilíndrica, 37 contenían un solo individuo y había nueve tumbas con dos individuos, dos tumbas contenían tres individuos, y tres tumbas contenían respectivamente cuatro, seis y nueve individuos enterrados en ellas (Costa y Llagostera 1994). Con excepción de un individuo en la tumba 23, todos los individuos estaban enterrados enfardados sentados y de cara hacia el oriente (Costa y Llagostera 1994). Los contextos incluían piezas de cerámica, calabazas, canastos, artefactos para inhalar alucinógenos, arcos y flechas de madera, herramientas de piedra, huesos de camélidos y restos de vegetales, tales como maíz y algarrobo (Costa y Llagostera 1994). Basándose en los análisis de los artefactos encontrados en las tumbas, los expertos argumentan que en el cementerio de Coyo-3 se enterraron dos grupos que coexistieron en el oasis (Costa y Llagostera 1994). El primer grupo (Grupo A) se caracterizaría por contextos pobres, sobre todo de origen local (Costa y Llagostera 1994). Los individuos del segundo grupo (Grupo B) fueron encontrados con un mayor número de productos extranjeros, tales como objetos asociados con el complejo alucinógeno, objetos metálicos y alfarería foránea (Costa y Llagostera 1994).

Finalmente, los fechados radiocarbónicos ubican cronológicamente al cementerio aproximadamente en 930 DC, fecha que es contemporánea con el Estado Tiwanaku (Costa y Llagostera 1994). Las fechas específicas son las siguientes: $990 \pm 50$ DC (tejidos de la tumba 5), 1040 \pm 70 DC (tejidos de la tumba 15), y 1030 \pm 80 DC (tejidos de la tumba 17) (Costa y Llagostera 1994).

\section{Coyo Oriental}

Al igual que Coyo-3, Coyo Oriental se emplaza en el ayllu de Coyo. Este cementerio fue excavado por primera vez por Gustavo Le Paige en 1971 y 1975, y sus entierros contienen grandes cantidades de objetos de estilo Tiwanaku tales como artefactos del complejo alucinógeno, junto a alfarería local "casi pulida", y que ha sido aceptada como evidencia contemporánea a la influencia de Tiwanaku en el oasis. La mayoría de los 399 individuos enterrados en las 216 tumbas en Coyo Oriental estaban enterrados en cistas. De las 216 tumbas, 135 tumbas contenían un solo individuo, aunque algunas de las tumbas parecían haber sido abiertas para acomodar entierros adicionales. Los individuos estaban enterrados en tejidos mortuorios y acompañados por una gran variedad de herramientas, armas, cerámicas, canastos y bolsas con alimentos, y también con artefactos del complejo alucinógeno (Bravo y Llagostera 1986; Llagostera et al. 1988). Debido a la excelente preservación en el sitio, 88 fardos contenían tejidos reconocibles.

De acuerdo a la alfarería de Coyo Oriental, se deduce que el cementerio fue utilizado entre los 500 y 900 DC, correspondientes a las fases Quitor (400-700 DC) y Coyo (700-1000 DC), momentos en los cuales se encuentran alfarería "casi pulida" y tabletas para alucinógenos con iconografía Tiwanaku (Berenguer et al. 1986, 1988). La identificación es respaldada con las siguientes fechas radiocarbónicas calibradas de Coyo Oriental: $639 \pm 20$ DC (tejidos de la tumba 5383), 672 \pm 60 DC (tejidos de la tumba 5341), $677 \pm 80$ DC (hueso de la tumba 4064), 677 \pm 50 DC (hueso de la tumba 4012), 888 \pm 1000 DC (hueso de la tumba 5347), y 910 $\pm 90 \mathrm{DC}$ (hueso de la tumba 4026) (Oakland 1992).

\section{Solcor-3}

El cementerio de Solcor-3 fue uno de los más grandes utilizados durante el Horizonte Medio en San Pedro de Atacama y se encuentra en el ayllu de Solcor. Excavaciones de salvataje conducidas por Llagostera y Bravo en 1983 permitieron encontrar 153 individuos enterrados en posiciones flexionadas en 93 tumbas (Bravo y Llagostera 1986). Estos individuos estaban enterrados en fosas cilíndricas envueltos en tejidos mortuorios. Los excavadores dividieron el cementerio en cuatro sectores de acuerdo a los artefactos encontrados en las tumbas, y al grado de perturbación de las mismas; el sector B ha sido relacionado con el 
altiplano por la calidad de productos de las tumbas tales como keros y tabletas para alucinógenos con iconografía Tiwanaku (Bravo y Llagostera 1986; Llagostera et al. 1988). Sesenta y cuatro individuos en 33 tumbas corresponden a la fase B, la cual está caracterizada por la existencia de objetos de estilo tiwanakota (Llagostera et al. 1988). De estas 33 tumbas, 15 contenían objetos relacionados con el complejo alucinógeno (Llagostera et al. 1988). Los objetos tiwanakotas encontrados en Solcor-3 se relacionan principalmente con el complejo alucinógeno, aun cuando un pequeño número de tejidos y de alfarería también fueron encontrados allí (Llagostera et al. 1988).

El cementerio estuvo en uso durante los años 400900 DC (Bravo y Llagostera 1986) y cubre tanto una fase pre-Tiwanaku, como una fase posterior que muestra evidencia de la influencia de Tiwanaku (Llagostera et al. 1988). Las fechas de radiocarbón de las tumbas con artefactos de estilo Tiwanaku son las siguientes: $480 \pm 60 \mathrm{DC}$ (tumba 117), 570 $\pm 60 \mathrm{DC}$

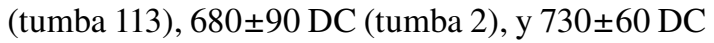
(tumba 107) (Llagostera et al. 1988; Torres-Rouff 2002). Estas fechas han sido corroboradas con las siguientes fechas obtenidas mediante la técnica de termoluminiscencia: $510 \pm 150$ DC (tumba 12), $560 \pm 145$ DC (tumba 67), 720 \pm 95 DC (tumba 50), $720 \pm 120$ DC (tumba 11), 720 \pm 95 DC (tumba 50), $850 \pm 110$ DC (tumba 41), y 920 \pm 120 DC (tumba 5) (Berenguer et al. 1986; Berenguer y Dauelsberg 1988; Llagostera et al. 1988).

\section{Introducción al análisis de los isótopos del estroncio}

Si bien los arqueólogos han utilizado el análisis de los isótopos del estroncio para determinar la procedencia de artefactos de piedra (Curran et al. 2001; Brilli et al. 2005), de vasijas (Freestone et al. 2003) y de maíz y de madera (English et al. 2001; Benson et al. 2003; Reynolds et al. 2005), la mayoría de los análisis de los isótopos del estroncio en arqueología ha sido útil para responder a preguntas sobre migración humana (Sealy et al. 1991, 1995; Price et al. 1994, 1998, 2000, 2001; Sillen et al. 1995, 1998; Ezzo et al. 1997; Grupe et al. 1997; Montgomery et al. 2000, 2003; Bentley et al. 2002, 2003; Ezzo y Price 2002; Farnum et al. 2003 Ms; Schweissing y Grupe 2003a, 2003b; Knudson 2004; Knudson et al. 2004, 2005; Wright 2005). Las diferencias en la relación de los isótopos del estroncio en el esmalte dental y huesos humanos pueden ser utilizadas para identificar los patrones de migración y el origen geológico de los inmigrantes (Ericson 1985, 1989; Krueger 1985 Ms; Sillen et al. 1989; Sealy et al. 1991; Price et al. 1994). El estroncio es incorporado al cuerpo humano a través del consumo de comida y de agua y, en menores cantidades a través de la respiración (Schroeder et al. 1972). A causa de la similitud en sus radios atómicos, el estroncio se sustituye para el calcio en la hidroxyapatita durante la etapa de desarrollo de los dientes y de los huesos (Hodges et al. 1950; Carr et al. 1962; Kulp y Schulert 1962; Dolphin y Eve 1963; Schroeder et al. 1972; Elías 1980; Elías et al. 1982; Lowenstam y Weiner 1989). Además, debido a que la diferencia de masa entre los diferentes isótopos del estroncio es muy pequeña, no ocurre fraccionamiento isotópico cuando los elementos son incorporados en la hidroxyapatita (Price et al. 2002). Como consecuencia, las relaciones de los isótopos del estroncio encontrados en los huesos y dientes de un individuo reflejan directamente la relación de los isótopos de las plantas, animales y agua que él o ella hayan consumido, lo que a su vez refleja las relaciones de los isótopos encontrados en el suelo y lecho rocosos de una determinada región geológica. Si el individuo consumió alimentos cultivados y cosechados localmente, las relaciones de sus isótopos del estroncio serán reflejo de la región geológica que habitó. Debido a que el esmalte dental no se regenera ni tampoco incorpora nuevos elementos después de su formación, los isótopos del estroncio en el esmalte dental reflejarán la región geológica que las personas habitaron durante el proceso de formación de dicho esmalte. Los huesos, por el contrario, están regenerándose constantemente y en forma tal que las proporciones de los isótopos en ellos reflejarán la región en la cual el individuo vivió justo antes de su muerte.

\section{Análisis de los isótopos del estroncio en San Pedro de Atacama}

Metodología de campo

La autora recogió muestras de los cementerios de Coyo Oriental, Coyo-3 y Solcor-3 del Museo R. P. Gustavo Le Paige s. j. en el verano de 2001. Las muestras dentales arqueológicas fueron limpiadas mecánicamente con un taladro inalámbrico Dremel Minimite-750 equipado con una fresa de grabado. Fueron limados aproximadamente de 5-10 mg de esmalte dental de la superficie bucal o lingual del diente, y fueron transportados a los Estados Unidos 
de Norteamérica con la autorización de Agustín Llagostera, Director del Instituto de Investigaciones Arqueológicas y Museo R. P. Gustavo Le Paige s. j., de la Universidad Católica del Norte.

Fueron diseñadas estrategias de muestreo para proveer una muestra representativa del $10-15 \%$ de cada cementerio, a la vez que se incluyeron individuos enterrados con productos foráneos o en contextos mortuorios atípicos o de acuerdo con las fechas obtenidas por la técnica de radiocarbón. Por ejemplo, la estrategia de muestreo en Coyo-3 fue diseñada con el objeto de aprovechar estudios anteriores de biodistancia y de deformaciones artificiales tanto del cráneo como de los artefactos. Un estudio de deformaciones artificiales de los cráneos en Coyo-3 muestra que, de 42 cráneos encontrados en el lugar, 37 presentaban deformaciones artificiales (Costa y Llagostera 1994). De éstos, el 95\% presentaba deformación de tipo tabular erecto, mientras que $2.5 \%$ mostraba deformación de tipo circular erecta y el restante $2.5 \%$, presentaba deformación oblicua circular. Como lo indicamos anteriormente, expertos habían determinado la existencia de dos grupos enterrados en Coyo-3; por consiguiente, individuos tanto del Grupo A como del Grupo B fueron incluidos en la muestra. En cuanto fue posible, individuos de tumbas fechadas con radiocarbón fueron incluidos en la muestra, así como también individuos atípicos, tales como los de la tumba 23. En general, 42 de 80 individuos enterrados en Coyo-3 tienen cráneos sin modificaciones; de estos 42 individuos, nueve fueron incluidos en este análisis.

La estrategia de muestreo en Coyo Oriental fue diseñada para ampliar análisis anteriores de tejidos mortuorios y de deformación artificial de los cráneos, con el fín de examinar la relación entre la identificación étnica, siendo determinada por los tejidos mortuorios, las deformaciones artificiales de los cráneos y los orígenes geográficos (Oakland 1992, 1994; Cocilovo y Zavattieri 1994; Varela 1997; Varela y Cocilovo 2000). Un examen de la deformación artificial de los cráneos de 158 individuos enterrados en Coyo Oriental muestra que 51\% de ellos mostraba una deformación de tipo tabular erecta, $7 \%$ presentaba deformación circular (anular) y $42 \%$ no mostraba ningún tipo de modificación craneal (Cocilovo y Zavattieri 1994). Por lo tanto, los individuos seleccionados fueron elegidos para ofrecer una muestra representativa de los diferentes tipos de deformaciones artificiales de los cráneos, así como también de los productos enterrados, tanto tiwanakotas como locales. En la medida de lo posible, individuos atípicos e individuos asociados a fechas radiocarbónicas fueron también incluidos. De los 399 individuos enterrados en Coyo Oriental, 158 poseían cráneos intactos. De estos 158, 15 individuos fueron incluidos en este estudio.

Al igual que en Coyo-3 y en Coyo Oriental, la estrategia de muestreo en Solcor-3 fue diseñada con el objeto de contribuir a ampliar la información disponible de estudios anteriores, al mismo tiempo que proveer una muestra representativa de individuos enterrados con y sin objetos tiwanakotas (Bravo y Llagostera 1986; Oakland 1986a; Llagostera et al. 1988; Neves y Costa 1998; Neves et al. 1999). Por ejemplo, el estudio de Torres-Rouff (2002) sobre deformación artificial de cráneos en Solcor-3 demostró que 53 de 92 individuos presentaban deformaciones artificiales; $72 \%$ de tales modificaciones eran de tipo tabular, mientras que otros tipos de deformación artificial, como por ejemplo anular, se mostraron en un $26 \%$, y frontal lo hicieron en un 2\% (Torres-Rouff 2002). En la medida de lo posible fueron incluidos en nuestra muestra individuos provenientes de tumbas fechadas por radiocarbón o por termoluminiscencia. En general, 92 de los 153 individuos enterrados en Solcor-3 tienen cráneos intactos; de estos 92 individuos, 16 fueron incluidos en el presente análisis.

Finalmente, fueron recolectadas muestras recientes y arqueológicas de fauna de la región suroriental de la cuenca del lago Titicaca, donde se localiza Tiwanaku, y de San Pedro de Atacama. Mediante el análisis de las proporciones de los isótopos del estroncio en pequeños mamíferos de varias regiones, se pueden determinar las proporciones locales de los isótopos del estroncio. En cada caso se recolectaron animales de familias que pudieran verificar que tales animales fueron criados en la localidad y alimentados con comida producida localmente. Cuando no fue posible la recolección de animales modernos, se incluyó fauna arqueológica de animales pequeños que vivían en la localidad.

\section{Metodología de laboratorio}

Todos los especímenes óseos y dentales fueron inicialmente preparados por la autora en el Laboratorio de Química Arqueológica de la Universidad de Wisconsin en Madison. Las muestras de animales frescos no fueron tratadas para diagénesis o contaminación postdeposicional, debido a que éstas no habían estado en contacto con posibles contaminan- 
tes. En su lugar, las muestras de animales frescos para el análisis de los isótopos del estroncio fueron colocadas en un crisol, y reducidas a cenizas a una temperatura de $800^{\circ} \mathrm{C}$ durante 10 horas, y después fueron molidas, utilizando mortero y manos de ágata. Antes de someterlas al análisis, las muestras de dientes arqueológicos fueron limpiadas mecánicamente con un taladro inalámbrico Dremel Minimite-750 equipado con una fresa de grabado. Esto removió cualquier materia orgánica adherida, y cualquier otro contaminante, así como también las capas más externas de los dientes, las cuales son las más propensas a contaminación diagénetica (Montgomery et al. 1999; Budd et al. 2000). Aproximadamente se removieron de 5-10 mg de esmalte dental con el taladro inalámbrico. Las proporciones de los isótopos del estroncio fueron obtenidas en el Laboratorio de Geoquímica Isotópica en el Departamento de Ciencias Geológicas de la Universidad de Carolina del Norte en Chapel Hill por el Dr. Paul Fullagar y por la autora, bajo la dirección del Dr. Paul Fullagar. Los detalles tanto de la preparación y del análisis de las muestras ya los hemos discutido (Knudson 2004; Knudson et al. 2004, 2005).

\section{Resultado de los isótopos del estroncio de San Pedro de Atacama}

\section{Relaciones isotópicas del Area Centro Sur Andina: Datos geológicos}

En general, las proporciones de los isótopos del estroncio alrededor del mundo varían entre ${ }^{87} \mathrm{Sr} /$ ${ }^{86} \mathrm{Sr}=0.7040 \mathrm{a}{ }^{87} \mathrm{Sr} /{ }^{86} \mathrm{Sr}=0.7200$ y están basados en la geología del lecho rocoso. En la cuenca del lago Titicaca, las cuencas de los ríos Tiwanaku y Katari están localizadas en el borde suroriental de dicho lago y están flanqueadas por cadenas montañosas (Lavenu 1991; Rodrigo y Wirmann 1991; Argollo et al. 1996; Binford y Kolata 1996). Las dos cadenas montañosas, la Cordillera Blanca y la Cordillera Real, están compuestas por andesitas paleozoicas, areniscas, y esquistos de barro rojo (Lavenu 1991; Rodrigo y Wirrmann 1991; Argollo et al. 1996; Binford y Kolata 1996). En las cuencas de los ríos, el lecho rocoso está compuesto por basaltos ígneos y andesitas y está recubierto de 10-20 $\mathrm{m}$ de sedimentos cuaternarios, fluviales y lacustres (Lavenu 1991; Rodrigo y Wirrmann 1991; Argollo et al. 1996; Binford y Kolata 1996). El agua de la superficie del lago Titicaca está caracterizada por ${ }^{87} \mathrm{Sr} /{ }^{86} \mathrm{Sr}=0.7082-0.7085$ y 20 muestras de cuatro núcleos sedimentales tomadas de dicho lago se carac- terizan por tener ${ }^{87} \mathrm{Sr} /{ }^{86} \mathrm{Sr}=0.7083-0.7087$ (Grove et al. 2003). En contraste, los análisis geológicos de las piedras volcánicas del Cenozoico Tardío de los Andes Centro Sur, al cual pertenece el oasis de San Pedro de Atacama, tienen ${ }^{87} \mathrm{Sr} /{ }^{86} \mathrm{Sr}=0.7062-0.7068$ (Rogers y Hawksworth 1989). De manera que las marcas de los isótopos del estroncio del lago Titicaca y del oasis de San Pedro de Atacama son diferentes y no coinciden.

Proporciones isotópicas en el centro sur andino: Datos de fauna moderna

A pesar de que la geología del Area Centro Sur Andina muestra que San Pedro de Atacama y la cuenca del lago Titicaca tienen diferentes proporciones de los isótopos del estroncio, los animales fueron analizados con miras a demostrar las proporciones de los isótopos del estroncio biológicamente disponibles en cada región. Los animales dan una idea más real de los valores locales de un área determinada, al hacer un promedio de las marcas, o huellas isotópicas, a lo largo de la región (Price et al. 2002). En el presente estudio, pequeños mamíferos con trayectorias de vida bien conocidas fueron tomados como muestra; en la mayoría de los casos, cuyes fueron usados como modelo de las marcas locales de los isótopos del estroncio.

En la cuenca del lago Titicaca existe una gran cantidad de cuyes silvestres, incluyéndose muestras de ellos en este estudio. Las proporciones de los isótopos del estroncio de las muestras óseas de tres cuyes silvestres, provenientes de tres lugares diferentes de la parte suroriental de la cuenca del Titicaca, indica que la marca local para dicha cuenca es ${ }^{87} \mathrm{Sr} /{ }^{86} \mathrm{Sr}=0.7083-0.7112$, que es la media de los valores del cuy más o menos dos desviaciones normales (Price et al. 2002). A pesar de que las proporciones de los isótopos del estroncio del suelo o del lecho rocoso de la cuenca del lago Titicaca no han sido analizadas, el análisis de los isótopos del estroncio de la superficie del agua y de los núcleos sedimentales coincidieron con el rango inferior de los valores de los cuyes (Grove et al. 2003).

En el oasis de San Pedro de Atacama, un solo cuy fue obtenido durante la recolección de muestras en el verano de 2001. Por lo tanto, la muestra de restos de animales de San Pedro de Atacama fue complementada con la inclusión de una tibia arqueológica de perro y de un ratón arqueológico, provenientes del cementerio Quitor-6. Los animales de la región de 
San Pedro de Atacama muestran también un rango característico local, el que no coincide con las marcas locales de la cuenca del lago Titicaca. El rango local en San Pedro de Atacama es ${ }^{87} \mathrm{Sr} /{ }^{86} \mathrm{Sr}=0.7074-0.7079$, y es la media de tres muestras de huesos de la fauna local más o menos dos desviaciones normales (Rogers y Hawkesworth 1989). Sin embargo, y como será discutido más adelante, la mayoría de las muestras de los cementerios de San Pedro de Atacama están entre ${ }^{87} \mathrm{Sr} /{ }^{86} \mathrm{Sr}=0.7074-0.7079$, lo cual sugiere que el modelo de los animales refleja con mayor exactitud el rango local de los habitantes de los oasis que datos geológicos.

Relaciones isotópicas de los individuos enterrados en San Pedro de Atacama

Como fue discutido previamente, individuos de Coyo-3 fueron analizados para determinar la existencia de individuos inmigrantes de la cuenca del Titicaca enterrados en el oasis junto a artefactos de estilo tiwanakota. Sin embargo, ningún individuo enterrado en Coyo-3 mostró la marca de los isótopos del estroncio de la cuenca del lago Titicaca en su esmalte dental (Figura 2 y Anexo 1). En efecto, solo un individuo $\left(\mathrm{CO} 3-46,{ }^{87} \mathrm{Sr} /{ }^{86} \mathrm{Sr}=0.706845\right)$ mostró una marca de los isótopos del estroncio, fuera del alcance local de San Pedro de Atacama $\left({ }^{87} \mathrm{Sr} /{ }^{86} \mathrm{Sr}=0.7074-0.7079\right)$. Este hombre, el cual tenía entre 40-44 años de edad en el momento de su muerte, estaba enterrado con artefactos de estilo tiwanakota, incluyendo una tableta de madera y un tubo para insuflar alucinógenos, así como también una ofrenda de camélido (Costa y Llagostera 1994). Sin embargo, a pesar de la inclusión de la tableta, claramente el hombre no vivió en la cuenca del lago Titicaca entre los tres y seis años de edad, esto último con base en el esmalte de su segundo diente molar.

De igual forma, existe la hipótesis de que individuos enterrados con artefactos de estilo Tiwanaku en Coyo Oriental eran inmigrantes de la cuenca del lago Titicaca. Sin embargo, ningún individuo enterrado en Coyo Oriental mostró una proporción de los isótopos del estroncio en su esmalte dental que estuviera dentro del alcance local de dicha cuenca, que es ${ }^{87} \mathrm{Sr} /{ }^{86} \mathrm{Sr}=0.7083-7112$ (Figura 3 y Anexo 1). $\mathrm{Si}$ bien no hay individuos que presentan la marca de la cuenca del Titicaca en su esmalte dental, hay dos individuos cuyo esmalte dental no corresponde a la marca del alcance local de San Pedro de Atacama.

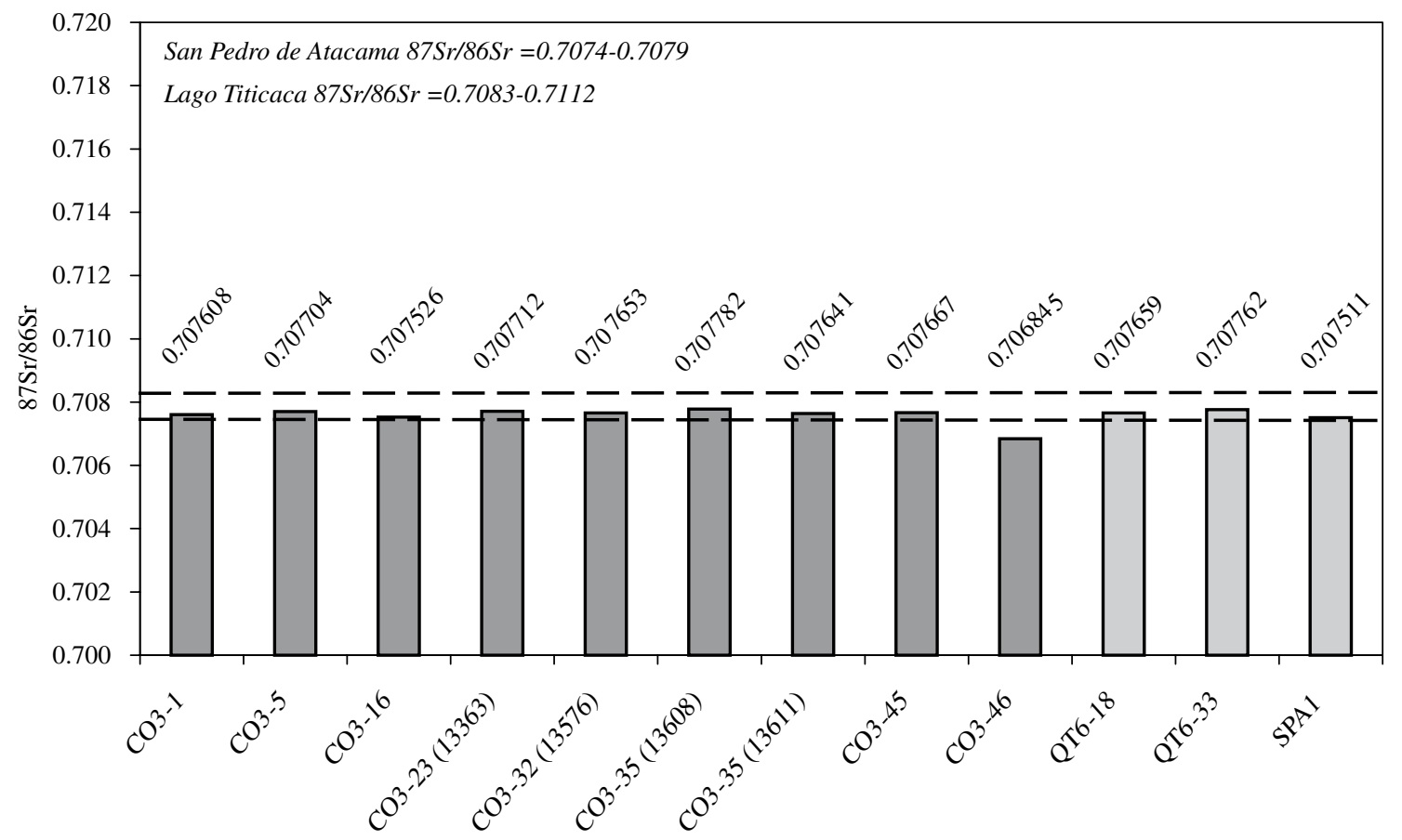

Figura 2. Proporciones de los isótopos del estroncio del esmalte dental humano arqueológico de Coyo-3 y de huesos de animales de San Pedro de Atacama. La línea punteada muestra el alcance de los valores locales de los isótopos del estroncio en San Pedro de Atacama. 


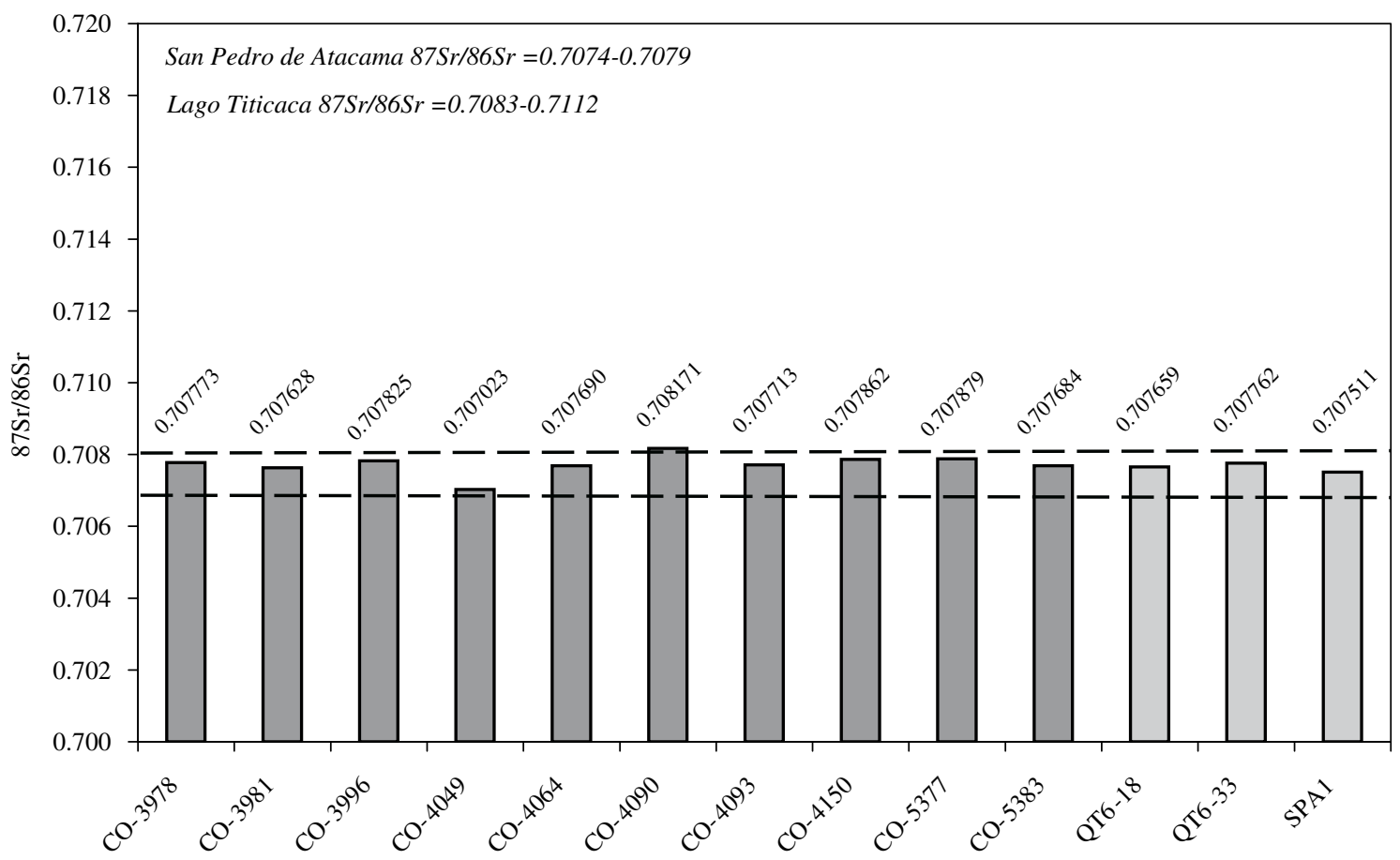

Figura 3. Proporciones de los isótopos del estroncio del esmalte dental humano arqueológico de Coyo Oriental, y de animales de San Pedro de Atacama. La línea punteada muestra el alcance de los valores locales de los isótopos del estroncio en San Pedro de Atacama.

Como vimos anteriormente, el rango local de San Pedro de Atacama es ${ }^{87} \mathrm{Sr} /{ }^{86} \mathrm{Sr}=0.7074-0.7079$. Este número es la media entre tres muestras óseas de la fauna local de San Pedro de Atacama, más o menos dos desviaciones normales (Price et al. 2002).

Estos dos individuos son adultos de sexo masculino, y uno de ellos tiene un valor de estroncio por debajo de la marca de San Pedro $\left(\mathrm{CO}-4049,{ }^{87} \mathrm{Sr} /{ }^{86} \mathrm{Sr}=0.707023\right)$, en tanto el otro tiene una marca de los isótopos del estroncio que está por encima de la marca local de San Pedro, pero que no cabe dentro de la marca de la cuenca del lago Titicaca $\left(\mathrm{CO}-4090,{ }^{87} \mathrm{Sr} /{ }^{86} \mathrm{Sr}=0.708171\right)$. Los dos individuos fueron enterrados con tejidos tiwanakotas y con tabletas para alucinógenos. Sin embargo, los otros individuos enterrados con material cultural de Tiwanaku en Coyo Oriental no vivieron en el altiplano durante la formación de su esmalte dental, debilitando el argumento de que una gran población del altiplano coexistió con la población local. Es posible que un solo individuo (CO-4090, ${ }^{87} \mathrm{Sr} /{ }^{86} \mathrm{Sr}=0.708171$ ) haya provenido de San Pedro de Atacama, por ser su proporción de los isótopos del estroncio similar a la media de la proporción de los isótopos del estroncio del esmalte dental de los individuos enterrados en el cementerio Solcor-3, la que es ${ }^{87} \mathrm{Sr} /{ }^{86} \mathrm{Sr}=0.708062 \pm 0.000083(1 \sigma, \mathrm{n}=8)$. Y como el cráneo de este individuo (CO-4090) no muestra modificación alguna, el tipo de deformación artificial del cráneo no afirma ni contradice esta hipótesis.

En comparación con Coyo-3 y Coyo Oriental existe una mayor variabilidad en las relaciones de los isótopos del estroncio encontrados en esmalte dental de Solcor-3 (Figura 4 y Anexo 1). De hecho, el mayor número de individuos foráneos encontrados en San Pedro de Atacama fueron enterrados en Solcor-3. Hubo nueve individuos, de una muestra de 16, que tenían proporciones de los isótopos del estroncio en el esmalte de sus primeros o segundos molares que no correspondían a la marca local de San Pedro de Atacama, que es de ${ }^{87} \mathrm{Sr} /{ }^{86} \mathrm{Sr}=0.7074-0.7079$. Además, de los 16 individuos de la muestra, cinco fueron enterrados en cuatro tumbas con artefactos locales; de estos cinco, solo un idividuo tenía una proporción de los isótopos del estroncio fuera del rango de la marca de San Pedro de Atacama. En contraste, seis de nueve individuos de la muestra, y que habían sido enterrados con por lo menos un artefacto de estilo tiwanakota, tenían proporciones de los isótopos del estroncio fuera de la marca de San 


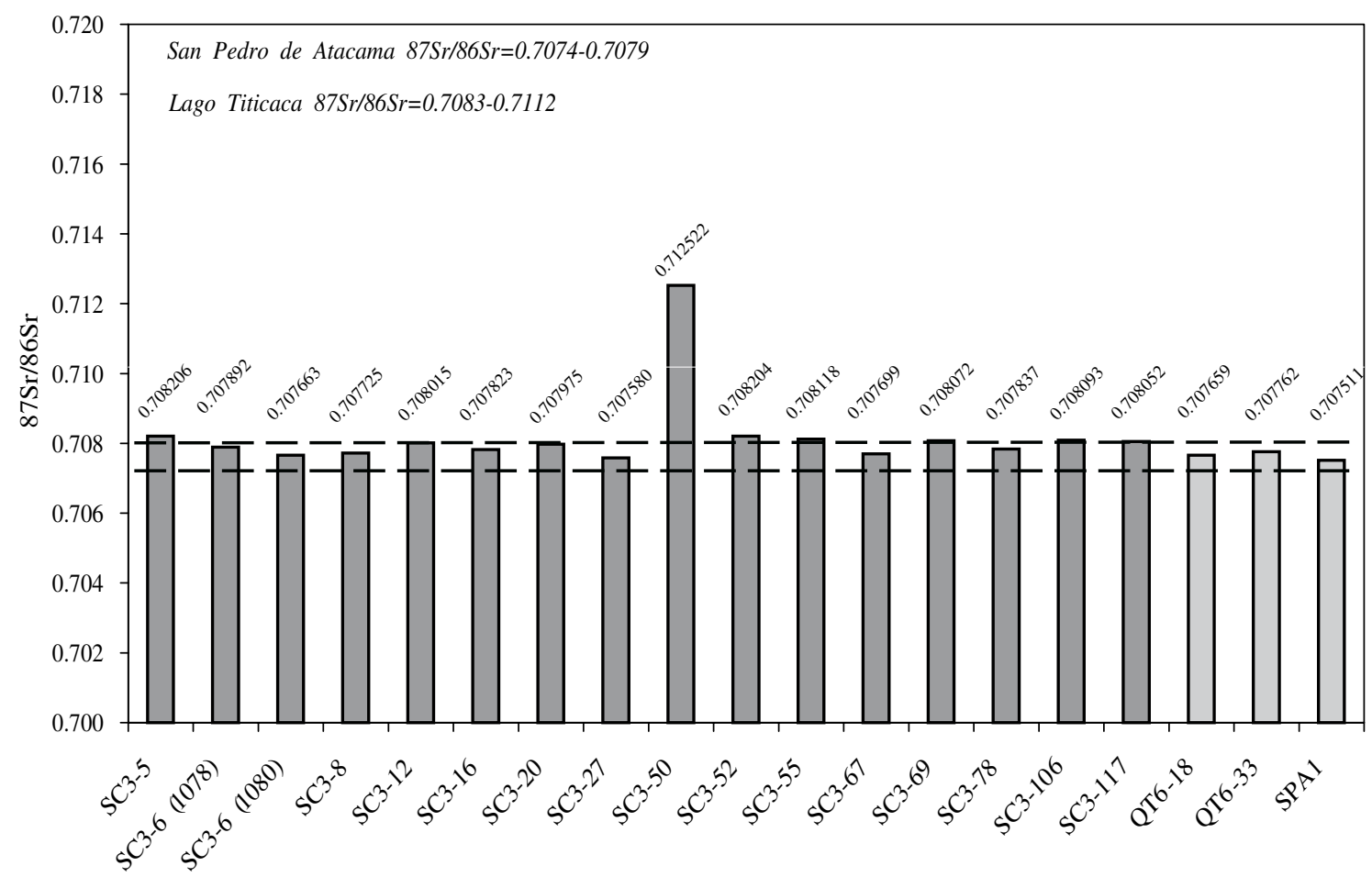

Figura 4. Proporciones de los isótopos del estroncio de esmalte humano arqueológico de Solcor-3 y de huesos de animales de San Pedro de Atacama. La línea punteada muestra el alcance local de los valores de los isótopos del estroncio en San Pedro de Atacama.

Pedro de Atacama. Finalmente, ambos individuos provenientes de tumbas de afiliación insegura no presentaban las proporciones locales de los isótopos del estroncio.

Sin embargo, de estos nueve individuos, solamente uno es claramente foráneo $\left(\mathrm{SC} 3-50,{ }^{87} \mathrm{Sr} /{ }^{86} \mathrm{Sr}=0.712522\right)$. A pesar de la hipótesis que plantea que algunos individuos enterrados en Solcor-3 eran inmigrantes de la cuenca del lago Titicaca, la relación de los isótopos del estroncio en los esmaltes dentales de estos individuos no está dentro de la marca local de los isótopos del estroncio de dicha cuenca $\left({ }^{87} \mathrm{Sr} /{ }^{86} \mathrm{Sr}=0.7083-0.7112\right)$. Los otros ocho individuos, quienes no tienen la marca local de los isótopos del estroncio en sus esmaltes dentales, están ligeramente fuera del rango local de San Pedro de Atacama. De hecho, para estos ocho individuos, la media del esmalte dental es ${ }^{87} \mathrm{Sr} /{ }^{86} \mathrm{Sr}=0.708062 \pm 0.000083(1 \sigma, \mathrm{n}=8)$, la cual es bastante cercana a la marca local de San Pedro de Atacama, que es ${ }^{87} \mathrm{Sr} /{ }^{86} \mathrm{Sr}=0.7074-0.7079$. Es probable que los individuos enterrados en Solcor-3 tuvieran acceso a terrenos en un lugar ligeramente diferente, o comieran una dieta diferente o más variada que aquellos individuos enterrados en Coyo-
3 y Coyo Oriental. El hecho de que seis de estos ocho individuos fueran enterrados con artefactos de estilo tiwanakota puede significar que individuos con acceso a tejidos, tabletas y cerámica de estilo Tiwanaku, también tenían un mayor acceso a alimentos no locales, o que tenían una dieta algo diferente a la de los individuos enterrados únicamente con artefactos locales.

La relación entre el sexo y los resultados de los isótopos del estroncio

En los cementerios de Coyo-3 y Solcor-3 las diferencias en la morfología facial y la elevada frecuencia de la deformación artificial del cráneo de tipo anular han llevado a algunos expertos a sugerir la hipótesis de exogamia femenina (Costa y Llagostera 1994; Torres-Rouff 2002). Sin embargo, en San Pedro de Atacama no hay indicación de que grandes cantidades de mujeres hubieran llegado desde otros lugares para vivir en las comunidades de los oasis. De hecho, todos los individuos claramente identificables en los cementerios Coyo-3, Coyo Oriental y Solcor-3 $\left(\mathrm{CO} 3-46,{ }^{87} \mathrm{Sr} /{ }^{86} \mathrm{Sr}=0.706845, \mathrm{CO}-4049\right.$, ${ }^{87} \mathrm{Sr} /{ }^{86} \mathrm{Sr}=0.707023, \mathrm{CO}-4090,{ }^{87} \mathrm{Sr} /{ }^{86} \mathrm{Sr}=0.708171$, 
y SC3-50, $\left.{ }^{87} \mathrm{Sr} /{ }^{86} \mathrm{Sr}=0.712522\right)$ eran adultos de sexo masculino. De modo que al oasis de San Pedro de Atacama no estaban llegando grandes cantidades de mujeres desde diferentes regiones geológicas en los Andes Centro Sur. Sin embargo, el movimiento desde otras comunidades que tenían la misma proporción de los isótopos del estroncio que San Pedro de Atacama no puede ser descartado.

Relación entre el estilo de la deformación artificial del cráneo y los resultados de los isótopos del estroncio

A lo largo de la Cordillera de los Andes, la deformación artificial del cráneo ha sido una forma importante para señalar la identidad (Gerszten 1993; Hoshower et al. 1995; Blom et al. 1998; Lozada 1998; Blom 1999, 2005; Lozada y Buikstra 2002; Torres-Rouff 2002). Y, puesto que el cráneo debe ser modificado durante los primeros años de vida de un individuo, esta es una forma irreversible de identificación étnica. Ello contrasta con el uso de la cultura material, como los textiles o la alfarería, para sugerir la identidad; estos últimos símbolos pueden ser cambiados o alterados durante la vida de un individuo, en la medida que las identidades cambian o aumentan con el paso del tiempo (Lozada y Buikstra 2002).

Al contrario de los incas, entre los cuales sólo las élites practicaban la deformación artificial del cráneo (de las Casas 1967), en el centro sur andino durante el Horizonte Medio esta práctica es sorpresivamente común y no está limitada a un grupo de élite (Dembo e Imbelloni 1938; Gerzsten 1993; Hoshower et al. 1995; Blom et al. 1998; Lozada 1998; Blom 1999, 2005; Lozada y Buikstra 2002; Torres-Rouff 2002). La deformación artificial del cráneo más asociada a Tiwanaku es la del tipo anular, también conocida como circunferencial (Dembo e Imbelloni 1938; Allison et al. 1981; Gerszten 1993; Blom et al. 1998; Blom 1999; Torres-Rouff 2002). La deformación artificial de tipo anular crea una cabeza alargada y estrecha y resulta de la presión uniforme a ambos lados del cráneo (Dembo e Imbelloni 1938; Blom 1999; Torres-Rouff 2002). La deformación artificial fronto-occipital puede ser de tipo tabular oblicua, en la cual la presión en el hueso occipital es paralela a la del hueso frontal, o tabular erecta, en la cual la presión en el cráneo es perpendicular a su base (Dembo e Imbelloni 1938; Blom 1999; Torres-Rouff 2002). La deformación artificial tabular oblicua fronto-occipital puede ser subdividida en los siguientes tipos: fronto-occipital plana, fronto-occipital redonda y fronto-occipital moderada. Otra clase de deformación artificial del cráneo es aquella conocida como tabular erecta o fronto-lambdoidal; en la del tipo tabular erecta, la presión en el cráneo es perpendicular a su base, en vez de ser paralela al hueso frontal, como en la forma tabular oblicua (Torres-Rouff 2002).

En San Pedro de Atacama la deformación artificial fronto-occipital es mucho más común que la anular, y la tabular erecta es más común que en la cuenca del lago Titicaca o que en la región alta del drenaje del río Osmore (Cocilovo y Zavattieri 1994; Torres-Rouff 2002). Sin embargo, el porcentaje de personas enterradas con cráneos deformados intencionalmente en los cementerios de San Pedro de Atacama es mucho menor que en los sitios del drenaje del Osmore. Por ejemplo, en Solcor-3, 53 (58\%) de 92 cráneos, mostraban deformaciones artificiales (Torres-Rouff 2002). De igual forma, en Coyo Oriental, 92 (58\%) de 158 cráneos estaban deformados artificialmente (Cocilovo y Zavattieri 1994), y los cráneos sin modificación alguna sobrepasaban en número a los cráneos deformados intencionalmente, en todas las épocas, en una gran parte de los cementerios de San Pedro de Atacama (Varela 1997; Torres-Rouff 2002). En efecto, TorresRouff (2002: 169) señala que:

"The lack of any striking annular vault modification, together with the predominant use of the tabular erect form, helps in refuting the notion that there was a large physical presence of Tiwanaku peoples in San Pedro de Atacama".2

En San Pedro de Atacama, los datos de las deformaciones artificiales del cráneo son respaldados por el estudio de los isótopos del estroncio, los cuales no arrojaron identificación alguna de inmigrantes de la región suroriental de la cuenca del Titicaca enterrados en los cementerios de los oasis san pedrinos. Igualmente, no es clara la relación entre los pocos individuos que pudieran ser inmigrantes al oasis y las deformaciones artificiales del cráneo. Por ejemplo, el único individuo claramente foráneo enterrado en Solcor-3 (SC3-50, $\left.{ }^{87} \mathrm{Sr} /{ }^{86} \mathrm{Sr}=0.712522\right)$ presentaba una deformación

\footnotetext{
2 "La carencia de alguna notable deformación anular, junto a la presencia predominante de la forma tabular erecta, ayuda a refutar la noción de que había una gran presencia física de gentes de Tiwanaku en San Pedro de Atacama".
} 
artificial fronto-occipital (C. Torres-Rouff, com. pers. 2002). Siete de los 53 individuos enterrados en Solcor-3 exhibían este tipo de deformación artificial del cráneo, haciendo de éste el tipo menos común en el cementerio (Torres-Rouff 2002). Sin embargo, los otros tres individuos, con deformaciones artificiales fronto-occipitales, los cuales fueron incluidos en el análisis de los isótopos del estroncio, no mostraron proporciones anómalas de los isótopos del estroncio en sus esmaltes dentales. Además, no había correlación entre el tipo de deformación artificial del cráneo y la proporción de los isótopos del estroncio del esmalte dental, en Solcor-3. De igual forma, Torres-Rouff (2002) no encontró correlación entre el tipo de deformación artificial del cráneo y la presencia de productos de estilo tiwanakota en Solcor-3.

En Coyo Oriental uno de los individuos identificado como extranjero $\left(\mathrm{CO}-4049,{ }^{87} \mathrm{Sr} /{ }^{86} \mathrm{Sr}=0.707023\right)$ presenta una deformación artificial de tipo tabular erecta, la cual es típica de San Pedro de Atacama, mientras que el otro individuo extranjero (CO$\left.4090,{ }^{87} \mathrm{Sr} /{ }^{86} \mathrm{Sr}=0.708171\right)$ presenta un cráneo sin modificación (J. Cocilovo, com. pers. 2003). El único individuo con deformación artificial de tipo anular, típica del altiplano, y el que fue incluido en este estudio de los isótopos del estroncio, tenía una proporción local de los isótopos del estroncio en su esmalte dental $\left(\mathrm{CO}-5377,{ }^{87} \mathrm{Sr} /{ }^{86} \mathrm{Sr}=0.707879\right)$. Nuevamente, estos datos debilitan la hipótesis de que individuos con deformación artificial de tipo anular son immigrantes de Tiwanaku.

\section{Discusión general}

Como ya fue mencionado, es posible que algunos individuos hayan sido identificados como extranjeros, por causa del consumo de comidas no locales. Sin embargo, los productos dentro de las tumbas en los cementerios Coyo-3, Coyo Oriental y Solcor-3 incluyen maíz, algarrobo, huesos de camélidos y conchas de agua dulce (Oakland 1992; Costa y Llagostera 1994). El maíz como el algarrobo crecen en los oasis de San Pedro de Atacama, y los camélidos pueden ser mantenidos en las quebradas cercanas. Aunque las conchas de agua dulce y los peces provienen de las yungas orientales y/o del Pacífico, es posible que no hayan tenido gran importancia en la dieta de los habitantes de San Pedro de Atacama. En consecuencia, no hay razón para creer que grandes cantidades de comida importada alteraron las relaciones de los isótopos del estroncio.
El vínculo más notable entre los productos en las tumbas y los resultados de los isótopos del estroncio se encontró en los cementerios de San Pedro de Atacama. Basándose en la presencia de tejidos mortuorios tiwanakotas, Oakland (1992: 336) señala que:

"Strong Tiwanaku influence undoubtedly did disrupt the San Pedro cultural sequence, but there were most likely many people physically present whose original home was the Bolivian altiplano."3

Similarmente, Kolata (1993b: 277) escribe:

"Given the richness, complexity, and beauty of these distinctive textiles, the dead entombed in the Coyo cemetery were most likely themselves Tiwanaku elite dispatched to the Atacama region as representatives of the State." 4

Estudios de distancia biológica han sido utilizados también para apoyar la hipótesis que una población de immigrantes del altiplano existía en San Pedro de Atacama (Varela 1997; Varela y Cocilovo 2000).

Sin embargo, ninguno de los 27 individuos enterrados en San Pedro de Atacama, incluidos en este estudio, exhibe la marca de los isótopos del estroncio del suroriente de la cuenca del lago Titicaca en su esmalte dental. Así pues, el análisis de los isótopos del estroncio no muestra la presencia de individuos provenientes de dicha cuenca en los cementerios de San Pedro de Atacama. Los resultados de la distancia biológica podrían ser explicados por un número creciente de comerciantes en el oasis, o al incremento del flujo genético entre las poblaciones del norte de Chile y el noroeste de Argentina, en vez de la existencia de immigrantes de Tiwanaku. De acuerdo con los resultados de los isótopos del estroncio, parece que la presencia de los tejidos mortuorios tiwanakotas, las tabletas y la alfarería en las tumbas en San Pedro de Atacama, no corres-

\footnotetext{
"Sin lugar a dudas, la fuerte influencia de Tiwanaku causó la disrupción en el orden cultural de San Pedro, pero seguramente hubo mucha gente físicamente presente cuya vivienda original estaba en el altiplano boliviano."

4 "Dada la riqueza, la complejidad y la belleza de estos tejidos notables, los muertos enterrados en el cementerio de Coyo fueron seguramente miembros de las élites Tiwanaku enviados a la región de Atacama como representantes del Estado."
} 
ponde con una immigración desde la cuenca del lago Titicaca. Por el contario, las élites san pedrinas pudieron haber incorporado algunos artefactos tiwanakotas dentro de los rituales funerarios, para demostrar vínculos religiosos o económicos con el Estado Tiwanaku. Por ejemplo, las siguientes tumbas en Coyo Oriental contenían tejidos de estilo Tiwanaku, tabletas para alucinógenos o alfarería: 3996, 4049, 5358, 5377, y 5383. Sin embargo, ninguna de estas tumbas contenian individuos que hubieran vivido en la región suroriental de la cuenca del Titicaca durante su niñez. Es también importante notar que, aún a pesar de los productos enterrados en una tumba, las tumbas en sí mismas fueron siempre cistas descubiertas que contenían un individuo enterrado en una posición flexionada y de cara al volcán Licancabur (Torres y Conklin 1995). En San Pedro de Atacama, la homogeneidad en los estilos de las tumbas es mejor indicador de la homogeneidad de la población que la presencia de productos foráneos enterrados.

Por lo tanto, los individuos enterrados con artefactos tales como tabletas para alucinógenos y tejidos de estilo tiwanakota, no provenían de la cuenca del lago Titicaca. En vez de identificar immigrantes de Tiwanaku, la presencia de artefactos de ese estilo en los cementerios de San Pedro de Atacama, identifica individuos de la localidad que tenían vínculos con el Estado Tiwanaku. Los diferentes análisis de los productos de las tumbas, de los tipos de tumbas, de las deformaciones artificiales de los cráneos y, por último, el análisis de los isótopos del estroncio, indican a una población local, enterrada en los cementerios de Coyo-3, Coyo Oriental y Solcor-3. Sin embargo, algunos individuos proclamaban su relación con el Estado Tiwanaku siendo enterrados con artefactos de estilo tiwanakota, además de locales. Quizás, de este modo reforzaban los vínculos con las élites del Estado altiplánico, o con las caravanas de comerciantes que traían productos desde Tiwanaku. Este hecho, a su vez, pudo haber incrementado su poder y su prestigio en San Pedro de Atacama. En forma alterna, una experiencia religiosa compartida puede ser la manifestada por la inclusión de objetos mortuorios de estilo Tiwanaku. De hecho, Torres y Conklin (1995) sostienen la hipótesis de que San Pedro de Atacama pudo haber sido un centro religioso, que tenía como punto focal la práctica de rituales relacionados con el uso de los objetos para el consumo de alucinógenos; si esto es cierto, entonces los individuos pudieron haber traído productos foráneos con ellos cuando viajaban a estos oasis desde otras regiones.

Aún más, el único individuo de San Pedro de Atacama enterrado con alfarería foránea, sin ser de estilo tiwanakota, y que fue incluido en este estudio $\left(\mathrm{CO} 3-23(13363),{ }^{87} \mathrm{Sr} /{ }^{86} \mathrm{Sr}=0.707712\right)$ caía también dentro de la marca local de San Pedro de Atacama. Esta era una mujer, de 40-44 años, enterrada en una posición atípica, en su lado izquierdo, con vasijas importadas probablemente de estilo Aguada del Noroeste Argentino, con una calabaza, una tortera de madera y un pequeño jarro de plata (Costa y Llagostera 1994). A pesar de la alfarería importada y de su irregular postura de entierro, ella no parece ser una immigrante de primera generación de fuera de la región geológica de San Pedro de Atacama.

\section{Conclusión}

De acuerdo a la presencia de individuos enterrados con artefactos de estilo tiwanakota, como los tejidos, se ha argumentado que una pequeña población de la élite de Tiwanaku de la cuenca del lago Titicaca estaba presente en el oasis de San Pedro de Atacama (Oakland 1992; Kolata 1993a). Sin embargo, el análisis de los isótopos del estroncio que he realizado no ha podido reconocer ningún individuo que haya vivido en la cuenca del Titicaca durante los primeros años de su vida, y que haya sido enterrado en los cementerios de San Pedro de Atacama. Aunque es posible que algunos individuos vivieran en la cuenca del Titicaca durante otros años de sus vidas, la falta de evidencia de los isótopos del estroncio en el esmalte debilita la hipótesis que sostiene que en San Pedro de Atacama vivió una colonia de individuos provenientes de Tiwanaku. Torres y Conklin (1995) también han señalado el hecho de que la ausencia de tumbas propiamente tiwanakotas en San Pedro de Atacama, no concuerda con el modelo que piensa que estos oasis sostuvieron una colonia de Tiwanaku. En efecto, las tumbas contienen una mezcla de artefactos tiwanakotas y locales, e incluso objetos del complejo alucinógeno como tabletas o tubos con iconografía tiwanakotas, e implementos de estilo local (Torres y Conklin 1995).

Como no hay evidencia por parte de los isótopos del estroncio de que una población derivada del altiplano habitó en San Pedro de Atacama, la relación entre Tiwanaku y los oasis san pedrinos no estaba basada en la colonización directa. $\mathrm{La}$ 
relación entre los individuos de ambos lugares seguramente incorporaba aspectos tanto económicos como religiosos o ideológicos. Por ejemplo, San Pedro de Atacama pudo haber constituido un lugar de aprovisionamiento de productos minerales y de minerales en bruto. También, la importancia del lugar como un oasis para las vitales rutas de caravanas no puede ser subestimada. Es posible, entonces, que personas de San Pedro de Atacama hayan comerciado o intercambiado los artefactos de estilo tiwanakota encontrados en sus cementerios. Sin embargo, Torres y Conklin (1995: 96) señalan que: "trading is a two-way affair, and it is difficult to identify San Pedro's half of the barter". ${ }^{5}$ A pesar de que la sal, el cobre, la lapislázuli y la turquesa pudieron haber sido intercambiados, existen otras fuentes para estos mismos productos en los Andes Centro Sur.

Además, el intercambio de artefactos de estilo tiwanakota por comida y agua en el oasis no alcanza a explicar por completo el predominio de los productos rituales de Tiwanaku en San Pedro de Atacama (Torres y Conklin 1995). El énfasis en tejidos con iconografías complejas y de parafernalia insuflatoria de estilo tiwanakota en los cementerios de San Pedro, sugiere la posibilidad de que un compartido sistema de creencias y de actividades rituales conectaba a San Pedro con Tiwanaku. De acuerdo con el modelo de un centro religioso, San Pedro habría sido un centro de actividad religiosa especializado en el uso de alucinógenos, e individuos venidos desde la región de la cuenca del Titicaca y de otros lugares más alejados llegaban a estos oasis para participar en estas actividades rituales (Torres y Conklin 1995). Sin embargo, este modelo no explica en forma adecuada la adopción de la cultura material por parte de los nativos de San Pedro de Atacama, o la inclusión de artefactos de estilo tiwanakota en las tumbas de sus cementerios. Alternativamente, los individuos que vivieron en San Pedro de Atacama pudieron haber adoptado actividades rituales tiwanakotas y/o una identidad tiwanakota en la medida en que ellos adoptaban los elementos materiales de la cultura altiplánica. Esta pudo haber sido una identidad puramente religiosa, la cual estaba siendo proclamada o fortalecida a través de la inclusión de artefactos mortuorios tiwanakotas. En forma alterna,

\footnotetext{
5 "El comercio es un asunto bilateral, y es difícil identificar el papel de San Pedro en el acto comercial."
}

la asociación con el poderoso Estado Tiwanaku, demostrada mediante la inclusión de ensamblajes de cultura material, pudo haber resultado en poder político para grupos corporativos, cuando estos enterraban a sus muertos.

La adopción de cultura material tiwanakota, y posiblemente de la identidad tiwanakota, por parte de los individuos enterrados en los cementerios de San Pedro de Atacama, no estuvo acompañada por una coerción militar o por el incremento de la violencia en el oasis. A pesar de que Giesso (2003) argumenta en forma convincente que la emergencia de la fabricación de puntas proyectiles líticas estandarizadas es contemporánea con la aparición de sitios afiliados a Tiwanaku fuera de la cuenca del lago Titicaca, hay poca evidencia de conflictos entre el territorio Tiwanaku y el oasis de San Pedro de Atacama. Por ejemplo, después de haber examinado 161 esqueletos de los cementerios Solcor-3, Quitor-6 y Coyo-3, Costa y colaboradores (1998), concluyeron que no hay indicadores bioarqueológicos de guerras o actividades militares. En efecto, los indicadores bioarqueológicos de salud y nutrición implican que el nivel de vida mejoró durante este período (Costa et al. 1998, 2004).

Si bien la presencia de artefactos de estilo tiwanakota en los cementerios de San Pedro de Atacama ha sido interpretada como evidencia de la presencia de un grupo de colonos provenientes de Tiwanaku, el análisis de los isótopos del estroncio de tres cementerios claves del Período Medio en San Pedro de Atacama (Coyo-3, Coyo Oriental y Solcor-3) no ha podido identificar ningún individuo que hubiera vivido durante su niñez en el área sur de la cuenca del lago Titicaca. Como conclusión, los isótopos del estroncio no arrojan evidencia alguna de que una significativa población de inmigrantes tiwanakotas haya vivido en San Pedro de Atacama.

Agradecimientos La autora agradece a las siguientes instituciones y organizaciones por el financiamiento para la recolección de muestras y su respectivo análisis: la National Science Foundation (NSF SBR9708001 y BCS-0202329), la Sociedad Geológica de América (beca número 6833-01), la Universidad de Wisconsin, Madison y la Sociedad Química Americana. Además, las siguientes personas permitieron el acceso invaluable tanto a las colecciones, como a la información de contexto, así como también asistieron en la recolección de las muestras: Jane E. Buikstra, Saul Cervantes, José Cocilovo, Maria 
Antonietta Costa, Erika Díaz, Agustín Llagostera, Amy Oakland Rodman, Macarena Oviedo, Francisco Téllez, Daniel Titichoca, Christina Torres-Rouff y Hugo Varela. También, James Burton y T. Douglas Price de el Laboratorio de Química Arqueológica de la Universidad de Wisconsin en Madison y Paul
Fullagar en el Laboratorio de Geoquímica Isotópica de la Universidad de Carolina Norte en Chapel Hill generosamente dieron acceso a los laboratorios, y capacitación en el análisis de los isótopos del estroncio. Finalmente, gracias a Luis Melodelgado por la traducción del inglés al castellano.

\section{REFERENCIAS CITADAS}

ALLISON, M. J., E. GERSTEAN, J. MUNIZAGA, C. SANTORO y G. FOCACCI, 1981. La práctica de la deformación craneana entre los pueblos andinos precolombinos. Chungara 7: $238-260$.

ARGOLLO, J., L. TICCLA, A. KOLATA y M. RIVERA. 1996. Geology, geomorphology, and soils of the Tiwanaku and Catari river basins. En Tiwanaku and its hinterland: Archaeology and paleoecology of an Andean civilization, vol. 1, A. Kolata (Ed.), pp. 57-88. Smithsonian Institution Press, Washington, D. C.

BENAVENTE, M. A., C. MASSONE y C. THOMAS, 1986. Larrache, evidencias atípicas. Tiwanaku en San Pedro de Atacama? Chungara 16-17: 67-73.

BENSON, L., L. CORDELL, K. VINCENT, H. TAYLOR, J. STEIN, G. L. FARMER y K. FUTA, 2003. Ancient maize from Chacoan great houses: Where was it grown? Proceedings of the National Academy of Sciences 100: 13111-13115.

BENTLEY, R. A., T. D. PRICE, J. LUNING, D. GRONENBRON, J. WAHL y P. D. FULLAGAR, 2002. Prehistoric migration in Europe: Strontium isotope analysis of early Neolithic skeletons. Current Anthropology 34: 799-804.

BENTLEY, R. A., R. KRAUSE, T. D. PRICE y B. KAUFMANN, 2003. Human mobility at the early Neolithic settlement of Vaihingen, Germany: Evidence from strontium isotope analysis. Archaeometry 45: 471-487.

BERENGUER, J., 1978. La problemática Tiwanaku en Chile: Visión retrospectiva. Revista Chilena de Antropología 1: $17-40$.

BERENGUER, J. y P. DAUELSBERG, 1988. El Norte Grande en la órbita de Tiwanaku (400 a 1200 DC). En Culturas de Chile: Prehistoria. Desde sus orígenes hasta los albores de la Conquista, J. Hidalgo, V. Schiappacasse, H. Niemeyer, C. Aldunate e I. Solimano (Eds.), pp. 129-180. Editorial Andrés Bello, Santiago.

BERENGUER, J., V. CASTRO y O. SILVA, 1980. Reflexiones acerca de la presencia de Tiwanaku en el norte de Chile. Estudios Arqueológicos 5: 81-92.

BERENGUER, J., A. DEZA, A. ROMAN y A. LLAGOSTERA, 1986. La secuencia de Myriam Tarrago para San Pedro de Atacama: Un test por termoluminiscencia. Revista Chilena de Antropología 5: 17-24.
BERENGUER, J., A. ROMAN, A. DEZA y A. LLAGOSTERA, 1988. Testing a cultural sequence for the Atacama Desert. Current Anthropology 29: 341-346.

BINFORD, M. W. y A. L. KOLATA, 1996. The natural and human setting. En Tiwanaku and its hinterland: Archaeology and paleoecology of an Andean civilization, vol. 1, A. Kolata (Ed.), pp. 23-56. Smithsonian Institution Press, Washington D. C.

BLOM, D. E., 1999. Tiwanaku regional interaction and social identity: A bioarchaeological approach. Doctoral Dissertation, University of Chicago, Chicago.

2005. Embodying borders: Human body modification and diversity in Tiwanaku society. Journal of Anthropological Archaeology 24: 1-24.

BLOM, D. E., B. HALLGRIMSSON, L. KENG, M. C. LOZADA y J. E. BUIKSTRA, 1998. Tiwanaku "colonization": Bioarchaeological implications for migration in the Moquegua Valley, Peru. World Archaeology 30: 238-261.

BRAVO, L. y A. LLAGOSTERA, 1986. Solcor-3: Un aporte al conocimiento de la Cultura San Pedro. Período 500 al 900 DC. Chungara 16-17: 323-332.

BRILLI, M., G. CAVAZZINI y B. TURI, 2005. New data of 87Sr/86Sr ratio in classical marble: An initial database for marble provenance determination. Journal of Archaeological Science 32: 1543.

BROWMAN, D. L., 1986. Prehispanic Aymara expansion, the southern altiplano, and San Pedro de Atacama. Estudios Atacameños 7: 236-252.

1997. Political institutional factors contributing to the integration of the Tiwanaku State. En Emergence and change in early urban societies, L. Manzanilla (Ed.), pp. 229-243. Plenum Press, Nueva York.

BUDD, P., J. MONTGOMERY, B. BARREIRO y R. G. THOMAS, 2000. Differential diagenesis of strontium in archaeological human dental tissues. Applied Geochemistry 15: 687-694.

CARR, T. E. F., G. E. HARRISON, J. F. LOUTIT y A. SUTTON, 1962. Movement of strontium in the human body. British Medical Journal 2: 773-775. 
COCILOVO, J. A. y M. V. ZAVATTIERI, 1994. Biología del grupo prehistórico de Coyo Oriental (San Pedro de Atacama, norte de Chile): II deformación craneana artificial. Estudios Atacameños 11: 135-143.

CONKLIN, W. J., 1983. Pucara and Tiwanaku tapestry: Time and style in a sierra weaving tradition. Nawpa Pacha: 1-44.

COSTA, M. A. y A. LLAGOSTERA, 1994. Coyo-3: Momentos finales del Período Medio en San Pedro de Atacama. Estudios Atacameños 11: 73-143.

COSTA, M. A., W. A. NEVES, A. M. DE BARROS, y R. BARTOLOMUCCI, 1998. Trauma y estrés en poblaciones prehistóricas de San Pedro de Atacama, norte de Chile. Chungara 30: 64-74.

COSTA, M. A., W. A. NEVES y M. HUBBE, 2004. Influencia de Tiwanaku en la calidad de vida biológica de la población prehistórica de San Pedro de Atacama. Estudios Atacameños 27: $103-116$.

CURRAN, J. M., I. G. MEIGHAN, D. D. A. SIMPSON, G. ROGERS y A. E. FALLICK, 2001. 87Sr/86Sr: A new discriminant for provenancing Neolithic porcellanite artifacts from Ireland. Journal of Archaeological Science 28: 713-720.

DE LAS CASAS, B., 1967. Apologética historia sumaria. Universidad Autónoma de México, México D. F.

DEMBO, A. y J. IMBELLONI, 1938. Deformaciones intencionales del cuerpo humano de carácter étnico. J. Anesi, Buenos Aries.

DOLPHIN, G. W. e I. S. EVE, 1963. The metabolism of strontium in adult humans. Physics of Medical Biology 8: 193-203.

ELIAS, M., 1980. The feasibility of dental strontium analysis for diet-assessment of human populations. American Journal of Physical Anthropology 53: 1-4.

ELIAS, R. W., Y. HIRAO y C. C. PATTERSON, 1982. The circumvention of the natural biopurification of calcium along nutrient pathways by atmospheric inputs of industrial lead. Geochimica et Cosmochimica Acta 46: 2561-2580.

ENGLISH, N. B., J. L. BETANCOURT, J. S. DEAN y J. QUADE, 2001. Strontium isotopes reveal distant sources of architectural timber in Chaco Canyon, Mexico. Proceedings of the National Academy of Sciences 98: 11891-11896.

ERICSON, J. E., 1985. Strontium isotope characterization in the study of prehistoric human ecology. Journal of Human Evolution 14: 503-514.

1989. Some problems and potentials of strontium isotope analysis for human and animal ecology. En Stable isotopes in ecological research, R. W. Rundel, J. R. Ehleringer y K. A. Nagy (Eds.), pp. 254-269. Springer-Verlag, Nueva York.

EZZO, J. A. y T. D. PRICE, 2002. Migration, regional reorganization, and spatial group composition at Grasshopper Pueblo, Arizona. Journal of Archaeological Science 29: 499-520.
EZZO, J. A., C. M. JOHNSON y T. D. PRICE, 1997. Analytical perspectives on prehistoric migration: A case study from east-central Arizona. Journal of Archaeological Science 24: 447-466.

FARNUM, J., R. J. SPEAKMAN, K. LIENHOP e I. SHIMADA, 2003 Ms. Diet, status and health at Sican: A test of ICP-MS as a tool for paleodietary reconstruction. Ponencia presentada en 66th Annual Meeting of the Society for American Archaeology, Milwaukee.

FREESTONE, I. C., K. A. LESLIE, M. THIRLWALL e Y. GORIN-ROSEN, 2003. Strontium isotopes in the investigation of early glass production: Byzantine and early Islamic glass from the Near East. Archaeometry 45: 19-32.

GERSZTEN, P. C., 1993. An investigation into the practice of cranial deformation among the pre-columbian peoples of Northern Chile. International Journal of Osteoarchaeology 3: 87-98.

GIESSO, M., 2003. Stone tool production in the Tiwanaku heartland. En Tiwanaku and its hinterland: Archaeological and paleoecological investigations of an Andean civilization: Volume 2, Urban and rural archaeology, A. Kolata (Ed.), pp. 363-383. Smithsonian Institution Press, Washington D. C.

GOLDSTEIN, P. y M. RIVERA, 2005. Arts of greater Tiwanaku: An expansive culture in historical context. En Tiwanaku: Ancestors of the Inka, M. Young-Sánchez (Ed.), pp. 150185. University of Nebraska Press, Lincoln.

GROVE, M. J., P. A. BAKER, S. L. CROSS, C. A. RIGSBY y G. O. SELTZER, 2003. Application of strontium isotopes to understanding the hydrology and paleohydrology of the altiplano, Bolivia-Peru. Paleogeography, Paleoclimatology, Paleoecology 194: 281-297.

GRUPE, G., T. D. PRICE, P. SCHROTER, F. SOLLNER, C. M. JOHNSON y B. L. BEARD, 1997. Mobility of Bell Beaker people revealed by strontium isotope ratios of tooth and bone: A study of southern Bavarian skeletal remains. Applied Geochemistry 12: 517-525.

HODGES, R. M., N. S. MACDONALD, R. NUSBAUM, R. STEARNS, F. EZMIRLIAN, P. SPAIN y C. MACARTHUR, 1950. The strontium content of human bones. Journal of Biological Chemistry 185: 519-524.

HOSHOWER, L. M., J. E. BUIKSTRA, P. S. GOLDSTEIN y A. D. WEBSTER, 1995. Artificial cranial deformation at the Omo M10 site: A Tiwanaku complex from the Moquegua Valley, Peru. Latin American Antiquity 6: 145-164.

KNUDSON, K. J., 2004. Tiwanaku residential mobility in the South Central Andes: Identifying archaeological human migration through strontium isotope analysis. Doctoral Dissertation, University of Wisconsin at Madison, Madison.

KNUDSON, K. J., T. D. PRICE, J. E. BUIKSTRA y D. E. BLOM, 2004. The use of strontium isotope analysis to investigate Tiwanaku migration and mortuary ritual in Bolivia and Peru. Archaeometry 46: 5-18. 
KNUDSON, K. J., T. TUNG, K. C. NYSTROM, T. D. PRICE y P. D. FULLAGAR, 2005. The origin of the Juch'uypampa Cave mummies: Strontium isotope analysis of archaeological human remains from Bolivia. Journal of Archaeological Science 32: 903-913.

KOLATA, A. L., 1993a. The Tiwanaku: Portrait of an Andean civilization. Blackwell, Oxford.

1993b. Understanding Tiwanaku: Conquest, colonization and clientage in the South Central Andes. En Latin American horizons, D. S. Rice (Ed.), pp. 193-224. Dumbarton Oaks Research Library and Collections, Washington D. C.

KRUEGER, H. W., 1985 Ms. Sr isotopes and Sr/Ca in bone, Poster presentado en Biomineralization Conference, Airlie House, Warrenton.

KULP, J. L. y A. R. SCHULERT, 1962. Strontium-90 in man. Science 136: 619-632.

LAVENU, A., 1991. Formación geológica y evolución. En El lago Titicaca: Síntesis del conocimiento limnológico actual, C. Dejoux y A. Iltis (Eds.), pp. 19-27. ORSTOM, La Paz.

LE PAIGE, G., 1961. Cultura de Tiahuanaco en San Pedro de Atacama. Anales 1: 19-23.

LlagosterA, A., 1996. San Pedro de Atacama: Nodo de complementariedad reticular. En La integración surandina cinco siglos después, X. Albó, M. I. Anatia, J. Hidalgo, L. Núñez, A. Llagostera, M. I. Remy y B. Revesz (Eds.), pp. 17-42. Universidad Católica del Norte, Antofagasta.

LLAGOSTERA, A., C. M. TORRES y M. A. COSTA, 1988. El complejo psicotrópico en Solcor-3 (San Pedro de Atacama). Estudios Atacameños 9: 61-98.

LOWENSTAM, H. A. y S. WEINER, 1989. On biomineralization, Oxford University Press, Oxford.

LOZADA, M. C., 1998. The Señorío of Chiribaya: A bioarchaeological study in the Osmore drainage of Southern Peru. Doctoral Dissertation, University of Chicago, Chicago.

LOZADA, M. C. y J. E. BUIKSTRA, 2002. El Señorío de Chiribaya en la costa sur del Perú. Instituto de Estudios Peruanos, Lima.

MONTGOMERY, J., P. BUDD, A. COX, P. KRAUSE y R. G. THOMAS, 1999. LA-ICP-MS evidence for the distribution of lead and strontium in Romano-British, medieval and modern human teeth: Implications for life history and exposure reconstruction. En Metals in antiquity, S. M. M. Young, A. M. Pollard, P. Budd y R. A. Ixer (Eds.), pp. 290296. BAR International Series, Oxford.

MONTGOMERY, J., P. BUDD y J. EVANS, 2000. Reconstructing the lifetime movements of ancient people: A Neolithic case study from Southern England. European Journal of Archaeology 3: 370-385.

MONTGOMERY, J., P. BUDD y T. NEIGHBOUR, 2003. $\mathrm{Sr}$ isotope evidence for population movement within the
Hebridean Norse community of NW Scotland. Journal of the Geological Society 160: 649-653.

NEVES, W. y M. A. COSTA, 1998. Adult stature and standard of living in the prehistoric Atacama Desert. Current Anthropology 39: 278-281.

NEVES, W., A. M. BARROS y M. A. COSTA, 1999. Incidence and distribution of postcranial fractures in the prehistoric population of San Pedro de Atacama, Northern Chile. American Journal of Physical Anthropology 109: 253-258.

NUÑEZ, L., 1991. Cultura y conflicto en los oasis de San Pedro de Atacama. Editorial Universitaria, Santiago.

OAKLAND, A., 1986a. Tiahuanaco tapestry tunics and mantles from San Pedro de Atacama, Chile. En The Junius B. Bird conference on Andean textiles, A. Pollard Rowe (Ed.), pp. 101-121. The Textile Museum, Washington D. C.

-1986b. Tiwanaku textile style from the South Central Andes, Bolivia and North Chile. Doctoral Dissertation, University of Texas, Austin.

- 1992. Textiles and ethnicity: Tiwanaku in San Pedro de Atacama, North Chile. Latin American Antiquity 3: 316-340.

_ 1994. Tradición e innovación en la prehistoria andina de San Pedro de Atacama. Estudios Atacameños 11: 109-120.

ORELLANA, M., 1984. Influencias altiplánicas en San Pedro de Atacama. Estudios Atacameños 7: 197-208.

1985. Relaciones culturales entre Tiwanaku y San Pedro de Atacama. Diálogo Andino 4: 247-267.

PRICE, T. D., C. M. JOHNSON, J. A. EZZO, J. ERICSON y J. H. BURTON, 1994. Residential mobility in the prehistoric Southwest United States: A preliminary study using strontium isotope analysis. Journal of Archaeological Science 21: 315-330.

PRICE, T. D., G. GRUPE y P. SCHROTER, 1998. Migration in the Bell Beaker Period of Central Europe. Antiquity 72: 405-411.

PRICE, T. D., W. D. MIDDLETON y L. MANZANILLA, 2000. Immigration and the ancient city of Teotihuacan in Mexico: A study using strontium isotope ratios in human bone and teeth. Journal of Archaeological Science 27: 903-913.

PRICE, T. D., R. A. BENTLEY, J. LUNING, D. GRONENBORN y J. WAHL, 2001. Prehistoric human migration in the Linearbankeramik of Central Europe. Antiquity 75: 593-603.

PRICE, T. D., J. H. BURTON y R. A. BENTLEY, 2002. The characterization of biologically available strontium isotope ratios for the study of prehistoric migration. Archaeometry 44: 117-136.

REYNOLDS, A. C., J. L. BETANCOURT, J. QUADE, P. JONATHAN PATCHETT, J. S. DEAN y J. STEIN, 2005. 87Sr/86Sr sourcing of Ponderosa Pine used in Anasazi 
great house construction at Chaco Canyon, New Mexico. Journal of Archaeological Science 32: 1061.

RIVERA, M., 1975. Una hipótesis sobre movimientos poblacionales altiplánicos y transaltiplánicos en las costas del norte de Chile. Chungara 5: 7-31.

RODRIGO, L. A. y D. WIRRMANN, 1991. Aspecto general de la sedimentación. En El lago Titicaca: Síntesis del conocimiento limnológico actual, C. Dejoux y A. Iltis (Eds.), pp. 39-45. ORSTOM, La Paz.

ROGERS, G. y C. J. HAWKESWORTH, 1989. A geochemical traverse across the north Chilean Andes: Evidence for crust generation from the mantle wedge. Earth and Planetary Science Letters 91: 271-285.

SCHROEDER, H. H., I. H. TIPTON y A. P. NASON, 1972. Trace metals in man: Strontium and barium. Journal of Chronic Diseases 25: 491-517.

SCHWEISSING, M. M. y G. GRUPE, 2003a. Tracing migration events in man and cattle by stable strontium isotope analysis of appositionally grown mineralized tissue. International Journal of Osteoarchaeology 13: 96-103.

2003b. Stable strontium isotopes in human teeth and bone: A key to migration events of the late Roman period in Bavaria. Journal of Archaeological Science 30: 1373-1383.

SEALY, J. C., N. J. VAN DER MERWE, A. SILLEN, F. J. KRUGER y H. W. KRUEGER, $1991.87 \mathrm{Sr} / 86 \mathrm{Sr}$ as a dietary indicator in modern and archaeological bone. Journal of Archaeological Science 18: 399-416.

SEALY, J., R. ARMSTRONG y C. SCHRIRE, 1995. Beyond lifetime averages: Tracing life histories through isotopic analysis of different calcified tissues from archaeological human skeletons. Antiquity 69: 290-300.

SERRACINO, G., 1980. Tiwanaku desde San Pedro de Atacama. Estudios Arqueológicos 5: 95-106.

1984. Interzonal relationships in the Southern Andes in the Late Prehistoric Period. En Social and economic organization in the prehispanic Andes, D. L. Browman, R. L. Burger y M. Rivera (Eds.), pp. 161-169. BAR International Series 194, Londres.

SILLEN, A., J. C. SEALY y N. J. VAN DER MERWE, 1989. Chemistry and paleodietary research: No more easy answers. American Antiquity 54: 504-512.

SILLEN, A., G. HALL y R. ARMSTRONG, 1995. Strontiumcalcium ratios $(\mathrm{Sr} / \mathrm{Ca})$ and strontium isotope ratios $(87 \mathrm{Sr} / 86 \mathrm{Sr})$ of Australopithecus robustus and Homo sp. from Swartkrans. Journal of Human Evolution 28: 277-285.

SILLEN, A., G. HALL, S. RICHARDSON y R. ARMSTRONG, 1998. 87Sr/86Sr ratios in modern and fossil food-webs of the Sterkfontein Valley: Implications for early hominid habitat preferences. Geochimica et Cosmochimica Acta 62: 2463-2473.

STANISH, C., 2003. Ancient Titicaca: The evolution of complex society in Southern Peru and Northern Bolivia. University of California Press, Berkeley.

STOVEL, E. M., 2002. The importance of being atacameño: Political identity and mortuary ceramics in Northern Chile. Doctoral Dissertation, State University of New York at Binghampton, Binghampton.

THOMAS, C., M. A. BENAVENTE y C. MASSONE, 1985. Algunos efectos de Tiwanaku en la cultura de San Pedro de Atacama. Diálogo Andino 4: 259-274.

TORRES, C. M., 1985. Estilo e iconografía Tiwanaku en las tabletas para inhalar substancias psicoactivas. Diálogo Andino 4: 223-245.

1987. The iconography of the prehispanic snuff trays from San Pedro de Atacama, Northern Chile. Andean Past 1: 191-245.

2001. Iconografía Tiwanaku en la parafernalia inhalatoria de los Andes Centro Sur. Boletín de Arqueología PUCP 5: $427-454$

2005. Tiwanaku snuffing paraphernalia. En Tiwanaku: Ancestors of the Inka, M. Young-Sánchez (Ed.), pp. 114135. University of Nebraska Press, Lincoln.

TORRES, C. M. y W. J. CONKLIN, 1995. Exploring the San Pedro de Atacama/Tiwanaku relationship. En Andean art: Visual expression and its relation to Andean beliefs and values, $\mathrm{P}$. Dransart (Ed.), pp. 78-108, Aldershot, Avebury.

TORRES-ROUFF, C., 2002. Cranial vault modification and ethnicity in Middle Horizon in San Pedro de Atacama, Chile. Current Anthropology 43: 163-171.

URIBE, M. y C. AGUERO, 2001. Alfarería, textiles y la integración del Norte Grande de Chile a Tiwanaku. Boletín de Arqueología PUCP 5: 397-427.

VARELA, H. H., 1997. La población prehistórica de San Pedro de Atacama: Composición, estructura y relaciones biológicas. Tesis Doctoral, Universidad Nacional de Río Cuarto, Río Cuarto.

VARELA, H. H. y J. A. COCILOVO, 2000. Structure of the prehistoric population of San Pedro de Atacama. Current Anthropology 41: 125-132.

WRIGHT, L. E., 2005. Identifying immigrants to Tikal, Guatemala: Defining local variability in strontium isotope ratios of human tooth enamel. Journal of Archaeological Science 32: 555-566.

YOUNG-SANCHEZ, M., 2005. The art of Tiwanaku. University of Nebraska Press, Lincoln. 
Anexo 1. Listado de muestras incluidas en el presente estudio (*: $\sin \mathrm{n}^{\mathrm{o}}$ de rasgo, tumba y/o información de edad y sexo debido a que son restos de animales).

\begin{tabular}{|c|c|c|c|c|c|c|c|c|}
\hline Sitio & $\begin{array}{c}\mathrm{N}^{\circ} \mathrm{de} \\
\text { laboratorio }\end{array}$ & $\begin{array}{c}\mathrm{N}^{\circ} \mathrm{de} \\
\text { espécimen }\end{array}$ & Rasgo & Tumba & Edad & Sexo & Muestra & ${ }^{87} \mathrm{Sr} /{ }^{86} \mathrm{Sr}$ \\
\hline Coyo-3 & F1652 & $\mathrm{CO} 3-1$ & 13208 & 1 & $40-44$ & M & URM1 & 0.707608 \\
\hline Coyo-3 & F1654 & $\mathrm{CO} 3-5$ & 13280 & 5 & $30-34$ & M & URM1 & 0.707704 \\
\hline Coyo-3 & F1656 & $\mathrm{CO} 3-16$ & 13291 & 16 & $45-49$ & M & URM1 & 0.707526 \\
\hline Coyo-3 & F1658 & CO3-23 (13363) & 13363 & 23 & $40-44$ & $\mathrm{~F}$ & ULM1 & 0.707712 \\
\hline Coyo-3 & F1661 & CO3-32 (13576) & 13576 & 32 & $25-29$ & $\mathrm{~F}$ & LLM2 & 0.707653 \\
\hline Coyo-3 & F1662 & CO3-35 (13608) & 13608 & 35 & $30-34$ & M & ULM1 & 0.707782 \\
\hline Coyo-3 & F1664 & CO3-35 (13611) & 13611 & 35 & $30-34$ & $\mathrm{~F}$ & LM1 & 0.707641 \\
\hline Coyo-3 & F1666 & $\mathrm{CO} 3-45$ & 13735 & 45 & $19-20$ & $\mathrm{~F}$ & LLM1 & 0.707667 \\
\hline Coyo-3 & F1668 & $\mathrm{CO} 3-46$ & 13746 & 46 & $40-44$ & M & LRM2 & 0.706845 \\
\hline Coyo Oriental & F1637 & CO-3978 & 13603 & 3978 & $40-44$ & M & ULM2 & 0.707773 \\
\hline Coyo Oriental & F1638 & CO-3981 & 9975 & 3981 & $45-49$ & M & ULM1 & 0.707628 \\
\hline Coyo Oriental & F1639 & CO-3996 & 9976 & 3996 & $35-39$ & $\mathrm{~F}$ & URM2 & 0.707825 \\
\hline Coyo Oriental & F1641 & CO-4049 & 9870 & 4049 & $35-39$ & M & URM1 & 0.707023 \\
\hline Coyo Oriental & F1642 & $\mathrm{CO}-4064$ & 9860 & 4064 & $35-39$ & M & ULM2 & 0.707690 \\
\hline Coyo Oriental & F1643 & CO-4090 & 10042 & 4090 & $35-39$ & M & LRM1 & 0.708171 \\
\hline Coyo Oriental & F1644 & CO-4093 & 10041 & 4093 & $40-44$ & M & LLM1 & 0.707713 \\
\hline Coyo Oriental & F1645 & $\mathrm{CO}-4150$ & 9932 & 4150 & $40-44$ & $\mathrm{~F}$ & URM2 & 0.707862 \\
\hline Coyo Oriental & F1649 & CO-5377 & 9858 & 5377 & $35-39$ & $\mathrm{~F}$ & LRP2 & 0.707879 \\
\hline Coyo Oriental & F1651 & CO-5383 & 13597 & 5383 & $40-44$ & M & LRM1 & 0.707684 \\
\hline Quitor-6 & F1635 & QT6-18 & $*$ & 18 & * & A & hueso de ratón & 0.707659 \\
\hline Quitor-6 & F1636 & QT6-33 & $*$ & 33 & $*$ & A & tibia de perro & 0.707762 \\
\hline San Pedro & F1714 & SPA1 & $*$ & * & * & A & hueso de cuy & 0.707511 \\
\hline Solcor-3 & F1670 & $\mathrm{SC} 3-5$ & 1049 & 5 & $35-39$ & M & LRM1 & 0.708206 \\
\hline Solcor-3 & F1671 & SC3-6 (1078) & 1078 & 6 & $25-29$ & M & LLM1 & 0.707892 \\
\hline Solcor-3 & F1673 & SC3-6 (1080) & 1080 & 6 & $50-54$ & $\mathrm{~F}$ & ULM1 & 0.707663 \\
\hline Solcor-3 & F1675 & SC3-8 & 1161 & 8 & $40-44$ & $\mathrm{~F}$ & LRM2 & 0.707725 \\
\hline Solcor-3 & F1677 & SC3-12 & 1236 & 12 & $20-24$ & M & LLM1 & 0.708015 \\
\hline Solcor-3 & F1678 & SC3-16 & 3061 & 16 & $20-24$ & $\mathrm{~F}$ & LLM1 & 0.707823 \\
\hline Solcor-3 & F1679 & SC3-20 & 1456 & 20 & $30-34$ & M & LRM1 & 0.707975 \\
\hline Solcor-3 & F1680 & SC3-27 & 1628 & 27 & $40-44$ & $\mathrm{~F}$ & LLM1 & 0.707580 \\
\hline Solcor-3 & F1681 & SC3-50 & 1948 & 50 & $40-44$ & $\mathrm{M}$ & URM1 & 0.712522 \\
\hline Solcor-3 & F1684 & SC3-52 & 2025 & 52 & $30-34$ & M & LLM1 & 0.708204 \\
\hline Solcor-3 & F1686 & SC3-55 & 2113 & 55 & $30-34$ & M & ULM1 & 0.708118 \\
\hline Solcor-3 & F1688 & SC3-67 & 2428 & 67 & $30-34$ & $\mathrm{M}$ & URM1 & 0.707699 \\
\hline Solcor-3 & F1690 & SC3-69 & 2476 & 69 & $30-34$ & $\mathrm{M}$ & LRM2 & 0.708072 \\
\hline Solcor-3 & F1692 & SC3-78 & 2699 & 78 & $40-44$ & $\mathrm{M}$ & LLM1 & 0.707837 \\
\hline Solcor-3 & F1694 & SC3-106 & 13117 & 106 & fardo & fardo & LLM1 & 0.708093 \\
\hline Solcor-3 & F1695 & SC3-117 & 13156 & 117 & $25-29$ & M & LRM1 & 0.708052 \\
\hline $\begin{array}{l}\text { Cuenca del Titicaca } \\
\text { (Chiripa) }\end{array}$ & F1024 & Ch1A & $*$ & * & * & $*$ & hueso de cuy & 0.709291 \\
\hline $\begin{array}{l}\text { Cuenca del Titicaca } \\
\text { (Tiwanaku) }\end{array}$ & F1026 & T1A & * & * & * & * & hueso de cuy & 0.709368 \\
\hline $\begin{array}{l}\text { Cuenca del Titicaca } \\
\text { (Lukurmata) }\end{array}$ & F1025 & L2A & $*$ & * & * & * & hueso de cuy & 0.710561 \\
\hline
\end{tabular}

